\title{
Papers
}

\section{Interventions for basal cell carcinoma of the skin: systematic review}

\author{
Fiona Bath-Hextall, Jan Bong, William Perkins, Hywel Williams
}

\begin{abstract}
Objectives To assess the effects of treatments for basal cell carcinoma.

Methods Systematic review of randomised controlled trials. Main outcome measure Recurrence of basal cell carcinoma at three years or beyond, assessed clinically.

Studies reviewed Randomised controlled trials of interventions for histologically confirmed basal cell carcinoma (published and unpublished material; no language restrictions).

Results 25 studies were identified, covering seven therapeutic categories. Only one study of surgical excision versus radiotherapy contained primary outcome data, which showed significantly more persistent tumours and recurrences in the radiotherapy group compared with surgery (odds ratio 0.09 , $95 \%$ confidence interval 0.01 to 0.67 ). One study compared cryotherapy with surgery, with inconclusive results at one year. In a comparison of radiotherapy with cryotherapy, significantly more recurrences occurred at one year in the cryotherapy group. Preliminary studies suggest a short term success rate of $87-88 \%$ for imiquimod cream in the treatment of superficial basal cell carcinoma, although this cream has not been compared with surgery. No consistent evidence was found for the other treatment modalities.

Conclusions Little good quality research has been done on the treatments used for the most common cancer in humans. Most trials have included only people with basal cell carcinoma occurring at low risk sites. Only one trial measured recurrence at four years; recurrence rates at one year should be interpreted with caution. Surgery and radiotherapy seem to be the most effective treatments; surgery showed the lowest failure rates. Other treatments might have some use but need to be compared with surgery.
\end{abstract}

\section{Introduction}

Basal cell carcinoma (BCC) is a form of skin cancer and the most common cancer found in humans ${ }^{1-3}$; it has diverse clinical appearances and morphology. BCCs are usually slow growing tumours that rarely spread to distant parts of the body. ${ }^{4}$ Growth of BCC is usually localised to the area of origin; however, some BCCs can infiltrate tissues in a three dimensional fashion that may not be obvious on visual inspection. ${ }^{35}$ If left untreated, or inadequately treated, the BCC can cause extensive destruction of tissue, particularly on the face. The clinical course of BCG is unpredictable; it may remain small for years, or it may grow rapidly or proceed by successive spurts of extension of tumour and partial regression. ${ }^{6}$

The tumour may occur at any age, but the incidence of BCC increases markedly after the age of 40 . The incidence in younger people is increasing, however, possibly as a result of increased exposure to the sun. Risk factors are fair skin, tendency to freckle, ${ }^{7}$ high degree of sun exposure, ${ }^{8-10}$ excessive use of sun beds, previous radiotherapy, phototherapy, male sex, and genetic predisposition. ${ }^{11}$

The first line treatment of BCC is often surgical excision. Many alternatives are available, including curettage, cryosurgery, laser treatment, surgical excision with predetermined margins of clinically normal tissue, excision under frozen section control, Moh's micrographic surgery, radiotherapy, topical treatment, intralesional treatment, photodynamic therapy, immunomodulators, and chemotherapy. Although many treatments are used for BCC, little research is available that accurately compares these different treatment modalities against each other and for different types of tumour. With an increase in incidence of skin cancer, ${ }^{12}$ a good evidence base is important to inform treatment decisions.

\section{Methods}

We did a systematic review of randomised controlled trials under the auspices of the Cochrane Skin Group, the results of which are published in the Cochrane Library. ${ }^{13}$ We have updated the review for the purpose of this publication. We used standardised search strategies to do computer searches. ${ }^{14}$ We searched Medline (from 1966 to December 2003), Embase (from 1980 to December 2003), the Cochrane Skin Group specialised register (December 2003), and the Cochrane Library (2004, issue 1). We manually searched cited references from identified trials and recent review articles, and we contacted pharmaceutical companies and experts in the specialty. We included non-English papers, which we had translated.

Two reviewers (FB-H and JB) independently examined the full text of all studies identified as possible randomised controlled trials, included all studies that fitted the inclusion criteria, and recorded their methodological quality. We assessed the studies as high quality if randomisation and concealment of allocation were clear and analysis was done by intention to treat. We considered studies to be intermediate quality if it was not clear how randomisation was achieved or the analysis was not done by intention to treat. We examined the trials in detail and drew up a descriptive synthesis. We calculated a weighted treatment effect (using fixed effects) across trials and expressed the results as odds ratios (with 95\% confidence intervals) for dichotomous outcomes by using the Cochrane Collaboration's review manager software. We pooled dichotomous data only when trials had similar design, methods, and outcome measures. The main outcome examined was recurrence of BCC at three to five years,

A table of trials identified is on bmj.com 


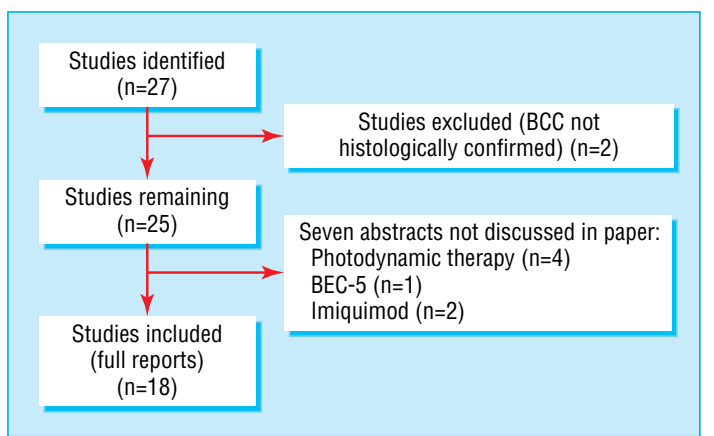

Fig 1 Flowchart of studies included in the review. BCC=basal cell carcinoma BEC-5=mixture of $0.005 \%$ solasodine glycosides found in solanaceous plants (aubergine)

measured clinically. Secondary outcomes included early treatment failure within six months, measured histologically; adverse effects; and discomfort to patients in terms of pain during treatment and thereafter. Studies relating to side effects have been described qualitatively.

\section{Results}

We identified 27 trials (fig 1). ${ }^{15-38}$ We excluded two papers because the tumours were diagnosed on clinical grounds or no reference was made to whether the BCC was confirmed by biopsy. ${ }^{31}{ }^{32}$ Details of included trials and excluded trials are available in the Cochrane Library. ${ }^{13}$ Seven studies were available only in abstract form and are not considered further in this report.

Evidence from the 18 included studies was generally limited, as only one trial contained long term data on our primary outcome.$^{15}$ Overall, we classified 14 trials as intermediate quality and four trials as high quality ${ }^{151930}$ (see table on bmj.com). Heterogeneity of the methods or failure to take into account the appropriate unit of analysis made the pooling of data impossible for many treatments. ${ }^{192}$ Full details of the studies, including types of study, sizes of lesions, and losses to follow up, are available in the Cochrane Library. ${ }^{13}$

\section{Surgical excision}

One randomised controlled trial of 347 patients compared surgical excision with frozen section margin control versus radiotherapy in primary $\mathrm{BCC}$ of the face less than $40 \mathrm{~mm}$ diameter. ${ }^{15}$ At four years significantly more persistent tumours and recurrences had occurred in the radiotherapy group than in the surgery group (odds ratio $0.09,95 \%$ confidence interval 0.01 to 0.67). Cosmetic outcome favoured surgery. ${ }^{39}$ After radiotherapy more than $65 \%$ of the patients developed dyspigmentations and telangiectasia, and radiodystrophy affected $41 \%$.

\section{Radiotherapy}

We found two randomised controlled trials of radiotherapy. These are described under surgical excision and cryotherapy. ${ }^{15} 16$

\section{Cryotherapy}

We found four randomised controlled trials of cryotherapy. ${ }^{16-18}{ }^{32}$ One is described in more detail under photodynamic therapy. ${ }^{18}$ Only two trials are considered here, as one of the trials did not confirm the tumours histologically. ${ }^{32}$

One study of 93 patients compared radiotherapy with cryotherapy for low risk primary BCC. ${ }^{16}$ Significantly more recurrences occurred in the cryotherapy group than in the radiotherapy group at one year-39\% (17/44) versus 4\% (2/49). Cosmetic results were not significantly different. The degree of pain and discomfort from the treated areas was the same in both groups. Hypopigmentation was more common than hyperpigmentation with both modes of treatment $(81 \%$ in the radiotherapy group and $88 \%$ in the cryotherapy group). Seven patients treated with radiotherapy developed some radiation telangiectasia.

A second study of 96 patients compared cryosurgery with surgical excision for superficial and nodular BCC of the head and neck. ${ }^{17}$ Recurrence rates at one year were not statistically different for cryosurgery and surgery-6.25\% (3/48) versus $0 \%$ $(0 / 48)$. Cosmetic results were generally better after surgery. Two patients $(4 \%)$ developed secondary wound infections in the first and second week after surgery, for which antibiotics were given. Patients in the cryotherapy group (90\%) complained of moderate to severe swelling of the treated area, with leakage of exudate from the defect.

\section{Photodynamic therapy}

Photodynamic therapy is a non-ionising radiation treatment modality under development that uses the interaction between visible light and tumour sensitising agents to cause cell death. We identified two randomised controlled trials of this treatment. Four trials in abstract form are not discussed here ${ }^{34-37}$ The first trial $(n=88)$ compared photodynamic therapy with cryotherapy for superficial and nodular BCCs. ${ }^{18}$ Recurrence rates at a year (histologically verified) were comparable-25\% (11/44) in the photodynamic therapy group and $15 \%(6 / 39)$ in the cryotherapy group. Clinical recurrences at one year were lower for photodynamic therapy (5\%) and cryosurgery (13\%). Scarring and tissue defects scored significantly better after photodynamic therapy. More patients indicated pain and discomfort during and after treatment with photodynamic therapy than with cryotherapy, although the difference was not statistically significant.

The second trial $(\mathrm{n}=83)$ compared the clinical and cosmetic outcome of superficial BCCs treated using either laser or broad band halogen light, in photodynamic therapy with topical 5-aminolevulinic acid. ${ }^{19}$ The analysis considered lesions rather than patients as the unit of analysis. Clinically verified early treatment failure was 14\% (16/111) of lesions for the laser and 18\% (24/134) of lesions for the broadband halogen group. No significant difference was found between the two light sources with regard to clinical response or cosmetic results. Discomfort was reported during illumination and during the first week after treatment (stinging, itching, pain, headache, sensation of warmth, or blushing). Multiple treatments were often needed.

\section{Intralesional interferon treatment}

We found four randomised controlled trials of intralesional interferon treatment, ${ }^{20-23}$ the results of which are summarised in figure 2 and in the full Cochrane review. ${ }^{13}$ Pain was experienced at the injection site in all studies, and all patients in the interferon groups experienced flu-like symptoms. Losses to follow up were mainly due to flu-like symptoms.

\section{Fluorouracil}

We identified two randomised controlled trials of fluorouracil. The first trial compared 5-fluorouracil cream 5\% in phosphatidyl choline vehicle to aid penetration versus 5 -fluorouracil $5 \%$ in petrolatum for non-superficial BCCs. ${ }^{24}$ No significant difference in early treatment failure, determined histologically, occurred in the phosphatidyl choline group compared with the petrolatum group $-10 \%(1 / 10)$ versus $43 \%(3 / 7)$; odds ratio $0.15,0.01$ to 1.90. The analysis considered lesions rather than patients. Local irritation, erythema, ulceration, and tenderness were common reactions. 


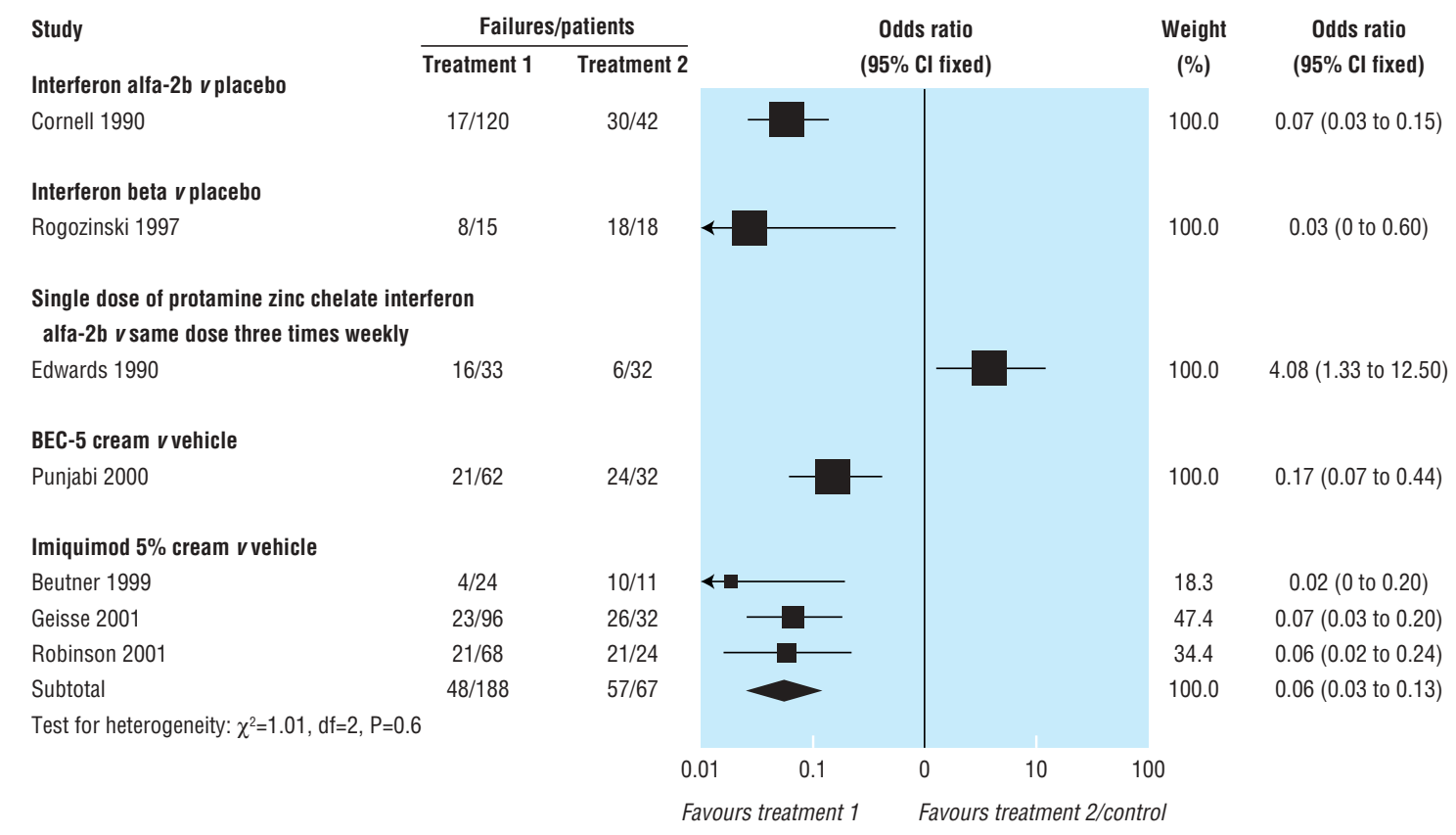

Fig 2 Early treatment failure within six months measured histologically. BEC-5=mixture of $0.005 \%$ solasodine glycosides found in solanaceous plants (aubergine)

The second open label randomised study of 122 patients tested the safety, tolerance, and efficacy of six treatment regimens of 5-fluorouracil/epinephrine gel for superficial and nodular BCCs. ${ }^{25}$ Two doses and four treatment schedules were used. All regimens seemed to work well, with no statistically significant differences among them. However, the wide confidence intervals indicate that large differences between regimens cannot be ruled out. Overall, the six regimens had an average early treatment failure of $9 \%$ on the basis of histological analysis and no significant differences occurred for any of these comparisons. All patients had transient, moderate to severe stinging, burning, or pain at the time of injection. Local tissue reactions were confined to the treatment site and included erythema, swelling, desquamation, erosions, and eschar in most patients.

\section{Imiquimod}

Seven trials assessed imiquimod. Three of the trials used similar regimens to evaluate the safety and efficacy of imiquimod $5 \%$ cream in the treatment of superficial and nodular, superficial only, and nodular only BCC..$^{27}{ }^{29}$ Pooled data from the three trials showed a significant reduction in early treatment failure in the $5 \%$ imiquimod group compared with the vehicle group-odds ratio $0.06,0.03$ to 0.13 (fig 2).

Two further dose response trials tested different dosage frequencies of imiquimod 5\% cream applied for six weeks for patients with primary superficial BCC and nodular BCC..$^{28}$ Higher dosage frequencies of 5\% imiquimod showed a trend towards fewer early treatment failures compared with lower dosage frequencies of $5 \%$ imiquimod in both trials (odds ratios 0.31 , 0.10 to 1.01 ; and $0.43,0.18$ to 1.01 ).

Two further dose response trials in superficial BCC $(n=93)$ and nodular BCC $(n=90)$ compared imiquimod 5\% cream with and without occlusion. ${ }^{30}$ Occlusion made no significant difference to early treatment failure for superficial BCC (odds ratio $0.66,0.29$ to 1.52 ) or nodular $\mathrm{BCC}$ (odds ratio $1.20,0.52$ to 2.75).

For all imiquimod trials drawbacks included redness, oedema, skin hardening, vesicles, erosion, ulceration, flaking, and scabbing at the treatment site. Local reactions were common, mostly mild to moderate, and well tolerated by patients and declined in incidence and severity with less frequent dosing. Two additional studies of imiquimod have been reported in abstract form but are not discussed here. ${ }^{38}$

\section{Discussion}

\section{Poor evidence base for most common human cancer}

Despite the enormous workload associated with the treatment of BCC, very little good quality research has been done on the efficacy of the treatment modalities used. Most studies have been done on low risk BCCs, the results of which are probably not applicable to tumours of the morphoeic type and those occurring in difficult areas such as the nasolabial fold or around the ears and eyes. Specific trials or subgroup analyses are needed for morphoeic tumours. Two trials randomised patients with multiple BCCs, whereas all other trials randomised patients with one BCC. Pooling of data was not possible in many cases, as the trials did not have similar designs, methods, or outcome measures. Operator differences should also be taken into consideration, especially for cryotherapy and photodynamic therapy.

As nearly two thirds of all recurrent tumours appear in the first three years after treatment, and 18\% appear between five and 10 years after treatment, our primary outcome measure for the review was recurrence at three to five years, measured clinically. Only one trial had a sufficient duration of follow up, and this found that the failure rate was significantly lower with surgery than with radiotherapy ${ }^{15}$ For the other trials recurrence rates are difficult to judge as two trials had a follow up period of two years, ${ }^{1623}$ four trials had a follow up period of one year, ${ }^{21} 151718$ and 12 trials had a follow up period of six months or less. ${ }^{19} 202224$ 25 27-30 ${ }^{33}$ In general, the quality of the trials was poor. In 13 of the 18 trials the method of randomisation was not described or was unclear. Only four of the trials clearly showed that concealment of allocation was adequate. Only 12 of the 18 trials used an intention to treat analysis, and seven of those involved the therapeutic option imiquimod. Blinding of outcome assessment was done or attempted for most of the trials. 


\section{What is already known on this topic}

Basal cell carcinoma of the skin is the most common form of human cancer; many tumours recur years after apparent initial clearance, and most are locally destructive

Excisional surgery, curettage and cautery, radiotherapy, cryotherapy, and more recently photodynamic therapy and imiquimod are the main treatments used

\section{What this study adds}

Only one trial included adequate long term data on recurrences of basal cell carcinoma, showing that excisional surgery with frozen section control was more effective than radiotherapy

Radiotherapy is associated with significant long term cosmetic defects, and the evidence for curettage and cautery, cryotherapy, photodynamic therapy, and imiquimod is inconclusive

Simple long term studies that document site, size, and type of basal cell carcinoma are needed to compare these treatments against excisional surgery

\section{Strengths and limitations of this review}

Our search for all published randomised controlled trials was rigorous, with no language restriction. All studies were assessed for quality and only considered in the meta-analysis if they were sufficiently similar in terms of study participants, interventions, and outcomes. We have chosen a primary outcome that best informs clinical practice. As with all systematic reviews, we may have missed some published and unpublished reviews. Several randomised controlled trials of imiquimod and photodynamic therapy reported in abstract form are likely to be published soon. These will be included as an update in our Cochrane review. ${ }^{13}$ Caution should be used in generalising the results of this review to people with Gorlin syndrome and other genetic syndromes, as responsiveness to some treatment modalities such as radiotherapy may be very different.

We are aware of a large number of case series reports on the different treatment modalities for primary BCCs. These studies cannot be included in our review of randomised controlled trials. However, they have been reviewed elsewhere,${ }^{40}$ and the authors found that recurrence rates could not be compared owing to lack of uniformity in methods of reporting and were unable to propose general guidelines for the treatment of BCC.

Contributors: FB-H did the electronic searches. FB-H and JB were involved in writing the protocol. WP and HW gave advice on the protocol. FB-H and $\mathrm{JB}$ were involved in extraction and entry of data. WP and JB were involved in checking the data and the report. HW gave advice and edited the final versions of the review. FB-H was responsible for the overall management and writing of the review and is the guarantor.

Funding: None.

Competing interests: FB-H, JB, WP, and HW are all involved in running a five year randomised controlled trial comparing imiquimod against excisional surgery for the treatment of low risk superficial and nodular basal cell carcinoma, which is funded by Cancer Research UK.

Ethical approval: Not needed.

1 Telfer N, Colver G, Bowers P. Guidelines for the management of basal cell carcinoma Br J Dermatol 1999;141:415-23.

2 Preston D, Stern R. Nonmelanoma cancers of the skin. N Engl J Med 1992;327:1649-62.

3 Miller S. Biology of basal cell carcinoma (part 1). J Am Acad Dermatol 1991;24:1-13.

4 Lo J, Snow S, Reizner G. Metastatic basal cell carcinoma: report of twelve cases with a review of the literature.J Am Acad Dermatol 1991;24:715-9.
5 Breuninger H, Dietz K. Prediction of subclinical tumor infiltration in basal cell carcinoma. J Dermatol Surg Oncol 1991;17:574-8.

6 Franchimont C. Episodic progression and regression of basal cell carcinomas. Br J Dermatol 1982;106:305-10.

7 Gilbody J, Aitken J, Green A. What causes basal cell carcinoma to be the commonest cancer? Aust J Public Health 1994;18:218-21.

8 Zaynoun S, Ali L, Shaib J. The relationship of sun exposure and solar elastosis to basal cell carcinoma. J Am Acad Dermatol 1985;12:522-5.

9 Pearl D, Scott E. The anatomical distribution of skin cancers. Int J Epidemiol 1986;15:502-6.

10 Mackie R, Elwood J, Hawks J. Links between exposure to ultraviolet radiation and skin cancer: a report of the Royal College of Physicians. I $R$ Coll Physicians Lond 1987;21:91-6.

11 Schrieber M, Moon T, Fox S, Davidson J. The risk of developing subsequent nonmelanoma skin cancers. J Am Acad Dermatol 1990;23:1114-8.

12 Goodwin R, Roberts D. Skin cancer registration in the United Kingdom. Br J Dermatol 2001;145(suppl 59):17.

13 Bath F, Bong J, Perkins W, Williams H. Interventions for basal cell carcinoma of the skin. Cochrane Database Syst Rev 2003;(4):CD003412.

14 Clarke M, Oxman A. Optimal search strategy for RCTs. Cochrane Reviewers' Handbook 4.1 (updated June 2000). Oxford: Cochrane Collaboration, 2000 (appendix 5c).

15 Avril M, Auperin A, Margulis A, Gerbaulet A, Duvillard P, Benhamou E, et al. Basal cell carcinoma of the face: surgery or radiotherapy? Results of a randomized study. Br J Cancer 1997;76:100-6.

16 Hall V, Leppard B, McGill J, Kesseler M, White J, Goodwin P. Treatment of basal-cell carcinoma: comparison of radiotherapy and cryotherapy. Clin Radiol 1986;37:33-4.

17 Thissen M, Nieman F, Ideler A, Berretty P, Neumann H. Cosmetic results of cryosurgery versus surgical excision for primary uncomplicated basal cell carcinomas of the head and neck. Dermatol Surg 2000;26:759-64.

18 Wang I, Bendsoe N, Klinterberg C, Enejder A, Andersson-Engels S, Svanberg S, et al. Photodynamic therapy vs. cryosurgery of basal cell carcinomas: results of a phase III clinical trial. Br J Dermatol 2001;144:832-40.

19 Soler A, Angell-Petersen E, Warloe T, Tausjo J, Steen H, Moan J, et al. Photodynamic therapy of superficial basal cell carcinoma with 5-aminolevulinic acid with dimethylsulfoxide and ethylendiaminetetraacetic acid: a comparison of two light sources. Photochem Photobiol 2000;71:724-9.

20 Alpsoy E, Yilmaz E, Basaran E, Yazar S. Comparison of the effects of intralesional interferon alfa-2a, $2 \mathrm{~b}$ and the combination of $2 \mathrm{a}$ and $2 \mathrm{~b}$ in the treatment of basal cell carcinoma. J Dermatol 1996;23:394-6.

21 Cornell R, Greenway H, Tucker S. Intralesional interferon therapy for basal cell carcinoma. J Am Acad Dermatol 1990;23:694-700.

22 Edwards L, Tucker S, Perednia D, Smiles K, Taylor E, Tanner D, et al. The effect of an intralesional sustained-release formulation of interferon alfa-2b on basal cell carcinomas. Arch Dermatol 1990;126:1029-32.

23 Rogozinski T, Jablonska S, Brzoska J, Michalska I, Wohr C, Gaus W. Intralesional treatment with recombinant interferon beta is an effective alternative for the treatment of basal cell carcinoma: double-blind, placebo-controlled study. Prezeglad Dermatologiczny 1997;84:259-63.

24 Romagosa R, Saap L, Givens M, Salvarrey A, Lin He J, Hsia S, et al. A pilot study to evaluate the treatment of basal cell carcinoma with 5-flourouracil using phosphatidyl choline as a transepidermal carrier. Dermatol Surg 2000;26:338-40.

25 Miller B, Shavin J, Cognetta A, Taylor J, Salasche S, Korey A, et al. Nonsurgical treatment of basal cell carcinomas with intralesional 5-flourouracil/epinephrine injectable gel. J Am Acad Dermatol 1997;36:72-7.

26 Punjabi S, Cook I, Kersey P, Marks R, Finlay A, Sharpe G, et al. A double-blind, multicentre parallel group study of BEC-5 cream in basal cell carcinoma. Eur Acad Dermatol Venereol 2000;14(suppl 1):47-60.

27 Beutner K, Geisse J, Helman D, Fox T, Ginkel A, Owens M. Therapeutic response of basal cell carcinoma to the immune response modifier imiquimod 5\% cream.J Am Acad Dermatol 1999;41:1002-7.

28 Marks R, Gebauer K, Shumack S, Amies M, Bryden J, Fox T, et al. Imiquimod 5\% cream in the treatment of superficial basal cell carcinoma: results of a multicentre 6-week dose-response trial. J Am Acad Dermatol 2001;44:807-13.

29 Geisse J, Rich P, Pandaya A, Gross K, Andres K, Ginkel A, et al. Imiquimod 5\% cream for the treatment of superficial basal cell carcinoma: a double-blind, randomized, for the treatment of superficial basal cell carcinoma: a
vehicle-controlled study. JAm Acad Dermatol 2002;47:390-8.

30 Sterry W, Ruzicka T, Herrera E, Takwale A, Bichel J, Andres K, et al. Imiquimod 5\% cream for the treatment of superficial and nodular basal cell carcinoma: randomized studies comparing low-frequency dosing with and without occlusion. Br J Dermatol 2002;147:1227-36

31 Enejder A, Klinterberg C, Wang I, Andersson-Engels S, Bendsoe N, Svanberg S, et al. Blood perfusion studies on basal cell carcinomas in conjunction with photodynamic therapy and cryotherapy employing laser-doppler perfusion imaging. Acta Derm Venereol 2000;80:19-23.

32 Mallon E, Dawber R. Cryosurgery in the treatment of basal cell carcinoma. Dermatol Surg 1996;22:854-8.

33 Shumack S, Robinson J, Kossard S, Golitz L, Greenway H, Schroeter A, et al. Efficacy of topical 5\% imiquimod cream for the treatment of nodular basal cell carcinoma. Arch Dermatol 2002;138:1165-71.

34 Rhodes L, De Rie M, Engtrom Y. Photodynamic therapy using topical methyl aminolevulinate versus surgery for nodular basal cell carcinoma: results of a multicentre randomised prospective trial. Arch Dermatol 2004;140:17-23.

35 Foley P. A phase III randomized study comparing photodynamic therapy (PDT) using Metvix or placebo cream in nodular basal cell carcinoma (BCC). Aust J Dermatol 2003;44:A5.

36 Basset-Seguin N, Ibbotson S, Emtestam L. Photodynamic therapy using methyl aminolevulinate is as efficacious as cryotherapy in basal cell carcinoma, with better cosmetic results [abstract]. British Association of Dermatologists 83rd Annual Meeting, Brighton, July 2003. Br J Dermatol 2003;149(suppl 64):46.

37 Tope WD, Menter A, El-Azhary RA. Randomized prospective comparison of topical methylaminolevulinate photodynamic therapy versus placebo photodynamic therapy in nodular basal cell carcinoma [abstract]. 9th World Congress of Cancers of the Skin, Seville, Spain, May 2003. 
38 Caro I, Geisse JK, Lindholm J, Golitz L, Stampone P, Owens M. Efficacy and safety of imiquimod 5\% cream in the treatment of superficial basal cell carcinoma [abstract]. 12th Congress of the European Academy of Dermatology and Venereology, Barcelona, Spain, 15th-18th October 2003.

39 Petit J, Avril M, Margulis A, Chassagne D, Gerbaulet A, Duvillard P. Evaluation of cosmetic results of a randomised trial comparing surgery and radiotherapy in the treatment of basal cell carcinoma of the face. Plast Reconstr Surg 2000;105:2544-51.

40 Thissen M, Neumann H, Schouten L. A systematic review of treatment modalities for primary basal cell carcinoma. Arch Dermatol 1999;135:1177-83.

(Accepted 19 July 2004)

\section{doi 10.1136/bmj.38219.515266.AE}

Centre for Evidence-Based Dermatology, Queen's Medical Centre, Nottingham NG7 2UH

Fiona Bath-Hextall senior lecturer, school of nursing

Hywel Williams professor of dermato-epidemiology

Department of Dermatology, Queen's Medical Centre

Jan Bong consultant

William Perkins consultant

Correspondence to: F Bath-Hextall fiona.bath-hextall@nottingham.ac.uk 